\title{
Equitable and empowering participatory policy design strategies to accelerate just climate action
}

\section{Isatis M. Cintron-Rodriguez ${ }^{1,2}, \underline{\text { Haley A. Crim }}^{3}$, Deb L. Morrison $^{3,4}$, Frank Niepold $^{3,5}$, Jen Kretser ${ }^{3,6}$, William} Spitzer $^{3,7}$, Tom Bowman $^{8}$

${ }^{1}$ Rutgers University, Department of Environmental Sciences, New Brunswick, NJ

${ }^{2}$ Citizens Climate Lobby, Coronado, CA

${ }^{3}$ Climate Literacy and Energy Awareness Network, Boulder, CO

4University of Washington, Institute of Science and Math Education, College of Education, Seattle, WA

${ }^{5}$ National Oceanic and Atmospheric Administration, Climate Program Office, Silver Spring, MD

${ }^{6}$ The Wild Center, Tupper Lake, NY

${ }^{7}$ National Network for Ocean and Climate Change Interpretation, Boston, MA

${ }^{8}$ Bowman Change, Inc., Long Beach, CA

https://doi.org/10.38126/ISPG180203

Corresponding author: isatis.cintron@rutgers.edu

Keywords: climate empowerment; participatory policy design; climate governance; policymaking; climate learning; COP26; Talanoa

Executive Summary: Inter- and intra-country inequalities hamper adaptation and resilience capacity to climate change. Achieving a climate resilient future requires long-term visions, system-oriented approaches, cross-sector collaborations, and good climate governance, while centering on equity and justice in policy making. Central to these governance efforts is an informed and active society with concrete mechanisms to influence decision making. Action for Climate Empowerment (ACE) provides the framework to attain climate policy coherence that integrates the capacities and needs of all members of society into ambitious and effective strategies. This paper proposes a novel approach to policy making, applied to the co-creation of a national climate empowerment plan for the United States that encompasses local participation, leadership, and consent. The approach is based on a combination of participatory backcasting and the Talanoa process structure and principles of multi-level, transdisciplinary, transparency and inclusive dialogues. The proposed approach is beneficial for the advancement of ambitious, practical, and flexible plans with broad-based buy-in from stakeholders ranging from policymakers to relevant actors to frontline and marginalized communities to institutions.

\section{Background}

Few issues facing society are more urgent than reducing vulnerability to climate change impacts and transitioning to a low-carbon economy. For decades, scientists have focused on defining the drivers and impacts of climate change as well as technological innovations to mitigate and adapt to the threat. However, effectively addressing the global climate crisis also requires social, cultural, economic, and political solutions (Van der Linden et al. 2017; 
Campos et al. 2016). The combination of mature climate solution technologies, the rising profile of climate justice, and the need to rebuild large swaths of the economy and society in the wake of COVID-19 provides a unique opportunity to accelerate bold, equitable climate action across every facet of society.

Every person, community, organization, and government globally would ideally be engaged in this effort; however, social inequities inhibit many from fully engaging or having their innovations realized and their needs broadly shared, reducing the potential global response to climate change (Bullard et al. 2005). Disproportionate impacts of climate change with respect to privilege, power, and oppression are well documented (e.g., Bullard 1993; Bullard et al. 2016). For example, those living in poverty are often more likely to be less resilient to increased storm and flood damage or marginal crop yields resulting from shifts in precipitation or droughts. What is not as clearly understood by those in power is the wealth of innovations present in communities who have experienced inequities and have been forced to adapt with few resources. Frontline communities - those experiencing the first and worst impacts of climate change-are places of innovation and hope (Kang and Ajaja 2015). The voices and experiences of these communities must be lifted to share their learning and innovations more broadly. Indeed, the perspectives, innovations and resiliencies developed within such contexts may hold the key to mitigation and adaptation to climate change across the world. However, these critical perspectives can only be engaged once we shift the current power structures that inhibit such critical learning across communities (Haverkamp 2012).

Fostering sustainable adaptation, mitigation, and resilience strategies requires that governments, communities, and individuals have shared ownership in and power to address the climate crisis. This responsibility includes sharing experiences and innovative practices across varied communities and contexts, providing financial and physical resources, and co-designing local and national policy to support implementation of emergent solutions (Bang and Vossoughi 2016; Bhowmik et al. 2018). The best policy solutions cannot be effectively implemented if the public does not support political leaders to do so. The best technological solutions cannot be engaged if the organizations or people who would use them are unaware of what they are, what their benefits might be, or if they are not collaboratively designed to work within the social context of a community. Once implemented, climate solutions cannot endure if they privilege certain groups and uphold the power dynamics that created the crisis in the first place. To address the climate crisis on the time scale required, every sector of society must be informed, engaged, and have the agency and will to act in a multitude of ways, on a wide range of scales, with the best interests of their communities, humanity, and the planet in mind (Sautier et al. 2017).

This paper aims to inform how policymakers can codesign effective national and subnational climate and resilience strategies that support social engagement, inclusion, and equity. Here we describe an innovative, multi-stakeholder climate policy co-design process to support a justice-centered and community-based national climate empowerment plan for the United States. This work argues that policies at all levels of government should support a system of coherent, equitable, and intentional climate governance to maximize global climate change efforts on the time scale needed. The process outlined here challenges the status quo by lifting marginalized experiences and narratives into central design positions and provides guidance to shift towards a collaborative design approach. Although this paper focuses on the United States, the design principles engaged and the lessons learned are applicable to every context where humans organize around climate action efforts.

\section{Good governance, learning, and action for climate empowerment}

The way we talk about learning is highly variable across community, institutional, organizational, disciplinary, and international contexts. However, for climate policy to be most effective across such 
boundaries, we need to be explicit when using language to ensure we are communicating shared visions. In the context of this paper, we argue for policies that foster a system of learning to improve climate empowerment, defined in the following: "Climate empowerment is the practical, political, and personal process to understanding the complexities of the systemic drivers of climate change. These include historic and contemporary systems of oppression over marginalized groups; the capacity to exercise power to disrupt and transform unjust and unsustainable systems and vested interests; and the increased access to resources and opportunities for individual, collective, personal, and political action in response to and in anticipation of climate change and its impacts" (Kwauk and Casey 2021, 4).

Given this definition, learning centered around climate empowerment includes continual learning by government officials, scientists, community members, organizational leadership, educators, workers in all industries, and youth; this definition of climate empowerment shows how ubiquitous learning is. Within a given context, policies can draw on our distributed knowledge to learn from our collective cultural wealth (Yosso 2005).

How then is learning for climate empowerment critical for good climate governance? To ensure that equitable and effective climate policy is enacted, governments need to develop transparent and deliberative processes that can improve the engagement between decision-makers and the public, provide agency to socially marginalized groups, and inform those at risk on the frontlines of climate change impacts. Effective climate change education at all levels, civic engagement, and workforce development across the economy are critical for communities and businesses to take the initiative to build a climate resilient future but are unlikely to be enacted without public support. Deep emission reduction, long-term climate goals and resilience building require us to unlock all societal capacity. To ensure that governments have support for policies that accelerate actions at all scales, elected officials need public support; however, collective human behavioral and decision-making processes are often neglected in climate change mitigation and adaptation analysis (Creutzig et al. 2016; Van der Linden et al. 2017; Ghojeh et al. 2019; Leiserowitz 2019). According to the World Bank (2014), governance is defined as exercising authority by political, social, and economic institutions and the interaction between them. Here, we adopt the definition used by the UN System Task Team in their Governance and Development Think Piece, which describes governance as the mechanisms, processes and institutions through which individuals and stakeholders have the voice and power to enforce their rights, mediate differences and carry out their duties (UNDESA, UNDP, and UNESCO 2012). Decisions affecting climate impacts and actions are made at all levels of society from lifestyle changes to bold climate action (Leiserowitz 2019; Rare and The Behavioral Insights Team 2019).

As a result, climate governance often faces the following challenges: 1) polarization, 2) lack of public understanding, 3) time lag of the climate, social, technological, and political systems, 4) intergovernmental design challenges, 5) societal resistance, 6) cost and benefit understanding of multiple action pathways, and 7) variation in the extent of policy engagement by different levels of government (Borick and Rabe 2010; National Research Council 2011). The inherent complexity of climate change makes it difficult to develop and build public support for sound response strategies (Rabe 2010). Making the case for climate action is one of the leading challenges facing policy makers in initiating and sustaining ambitious climate action (Ghojeh et al. 2019). Successful climate adaptation, mitigation, and resilience depends upon engaging in an "all in" strategy where all levels of government, business, civil society, and community groups are all empowered as actors (Hale and Hultman 2020), an approach which requires that all active in this work address unjust power and decision-making practices. Engaging in participatory governance mechanisms can accelerate climate adaptation and mitigation 
efforts while at the same time creating new power dynamics that can disrupt existing injustices (Feola and Nunes 2014 Sprain 2016). Such efforts often involve learning across diverse community boundaries to ensure authentic climate empowerment as an essential design principle (Wolfram et al. 2019).

Climate empowerment is so fundamentally entwined with governance for climate change that six elements are embedded in Article 6 of the United Nations Framework Convention on Climate Change (UNFCCC) and were again restated as Article 12 of the Paris Agreement (UN General Assembly 1992; UN General Assembly 2015). These elements are collectively known as Action for Climate Empowerment (ACE) and provide the legal basis to accelerate climate action through education, training, public awareness, public participation, public access to information, and international cooperation (Figure 1). ACE provides the legal basis to accelerate climate action and has been named within these international policy documents as a way to promote transformative climate action through behavioral change across all scales of society. These changes include but are not limited to increasing meaningful and equitable public participation, building political will for bold climate strategies, and developing skills across sectors to join the just transition to a low-carbon economy. ACE is "about how everything we study or do is affected by climate change. It is about understanding the transformation to be able to act on it" (Figueres 2015). ACE is key to accelerating climate action as it equips and moves society at all levels to engage, mitigate, adapt, drive, and thrive in a changing world.

ACE reaffirms and overlaps with environmental justice principles that are critical to build public engagement and create a sustainable and just society. When we consider ACE elements in conjunction with other international policy, such as the UN Declaration of Human Rights (UN General Assembly 1948) and the UN Declaration of the Rights of Indigenous Peoples (UN General Assembly 2007), it becomes clearer that learning for climate empowerment is not only entwined with traditional governance but also with new, innovative forms of just governance. Effectively designing and implementing ACE policies would enforce and institutionalize principles of informed consent, accountability, fairness, selfdetermination, and equitable public participation at every level of decision making. Such an approach would honor cultural integrity, be based on mutual respect, and acknowledge justice for all people. Transparency, openness, and participation are key to shifting towards a low-carbon and sustainable development model that discourages the culture of narrow, fragmented interests. Full implementation of an ACE approach to accelerating climate action means challenging how systems and governments work and interact. If we are to address the climate crisis, ACE is not optional or an add-on to existing climate policy; it is an essential framework for all climate action that makes development and implementation of strategies easier and faster for policymakers, ensures sustainable climate progress by creating public will to keep future governments accountable, and ensures that climate policy is equitable and representative of all voices.

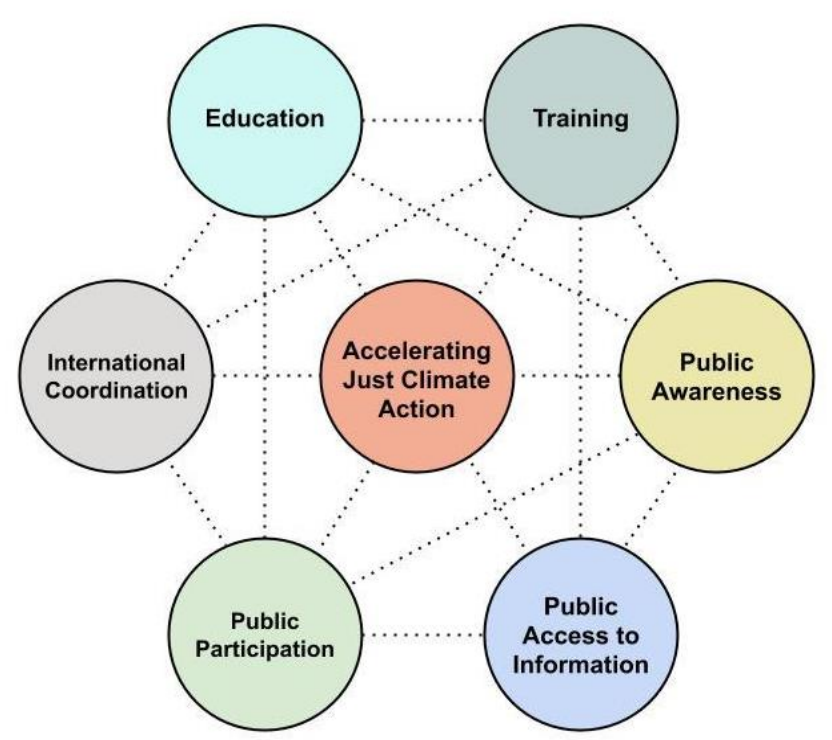

Figure 1: Action for Climate Empowerment pillars for accelerating just climate action (Morrison, 2020).

Good climate governance includes interactive decision making, engagement of complex networks of 
actors, dispersion of power and resources, diffused patterns of interdependence, active participation, and relational partnerships. People, governments, and organizations all need to share in, learn from, and leverage the broad community cultural wealth about climate action to accelerate efforts (Yosso 2005). Power and cultural norms are different across people, governments, and organizations, and such differences can limit ways that sharing knowledge and innovation occurs. People learn both in relationship to each other and more effectively when such relationships are sustained, trusting, and respectful (Pellow and Brulle 2005). Conversely, it is hard to learn from those whom we do not know, trust, or respect. This dependency highlights the importance of local knowledge and justice; governments have historically not attended to and leveraged local knowledge, often overriding or even trying to eliminate it. Such injustices need to be acknowledged and relationships repaired through consistent and sustained work by those historically in powerful positions engaging in justice-centered learning about and with those they serve.

Sustainable development as a process of long-term equitable change is attainable when there is a shared vision towards which we are all moving (Bibri 2018). This need for a shared vision is a complex facet of the work, as creating this shared vision is highly influenced by the other facets already named. To facilitate change, people, organizations, and governments need to have agency to act; they need to be able to actually make the changes possible. Decision making powers have historically been narrowly controlled, but going forward, decision makers need to consider more participatory processes to create truly effective, equitable, and broadly supported climate strategies (Bifulco 2013). Ensuring solid public acceptance of decisions as they are being made should involve not simply informing people of why a solution is needed, but also engaging the communities in co-designing policies so that there is a foundational commitment to ensuring the success of the solution locally, regionally, nationally, and ultimately, internationally.
ACE policies, as described by within United Nations documents, are intended to be enacted through national strategic plans (UNESCO and UNFCCC 2016; UNESCO 2020); however, there are several issues with current international and national ACE efforts. For example, there is an unbalanced and siloed implementation of ACE that lacks coordination between the elements. The result is fragmented and uncoordinated efforts that lack the scale, resources, and strategic capacity building efforts to ensure rapid climate actions. Additionally, there has been an implementation bias towards education, neglecting other elements such as public participation. ACE activities, in the absence of a coordinating ACE effort, are often not informed by research or best practices, often lacking monitoring mechanisms for tracking progress. For example, climate education efforts have focused on ensuring standards and curriculum but have done little to build administrators' or educators' capacity across systems to implement climate education using justice-centered pedagogical practices. Additionally, funding for ACE activity is largely an afterthought, deprioritized, or absent altogether. As a result, developing countries have struggled to garner international support to develop and implement ACE programs and marginalized communities within high emitting countries often lack political power to shape climate change responses. COP26 would provide a stage for determining a new ACE work program at the international level.

Even though countries are urged to implement a cross-cutting ACE national strategy (UNFCCC 2012), no high emitting national government or organization has yet provided a coordinating plan to create coherence among ACE efforts. This constellation of challenges facing existing ACE efforts and implementation activities and lack of coherent national strategies to align efforts highlights the underutilization of learning and awareness as a social innovation for accelerating just climate action. This results in duplications of effort and significant areas of missed opportunity for enacting climate 
adaptation and mitigation. Co-designing ACE strategies with policymakers, communities, and organizations and individuals already active in ACE can address these problems. We aim to provide a participatory practical guide to enact ACE by design that could be applicable to governments elsewhere in strengthening their climate plans in the road ahead of COP26 and beyond. We argue that ACE should be both leveraged as a policy development process and used as a methodology that governments and communities can use to coordinate and make coherent, broadly supported strategies to accelerate just climate action.

\section{Developing a climate empowerment methodology}

In 2020, as a result of the absence of federal climate leadership, the United States ACE community undertook an initiative to create An ACE National Strategic Planning Framework for the United States (referred to from herein as the ACE Strategic Planning Framework) using a justice-centered participatory design process. This process involved multi-level dialogues to collaborate and share insights to develop a shared vision for implementing ACE in the United States over a 20-year time period. The US ACE community is composed of formal and informal climate educators and institutions, youth, climate justice organizations, workforce development experts, climate and social scientists, behavior change researchers, climate communication professionals, elected officials, and others. This voluntary and unsanctioned process provided the flexibility to develop a meaningful participatory process to collaboratively design guidance for future national government efforts to develop and implement just and community-centered national climate policy for climate empowerment. This collaborative approach created a sense of ownership and engagement that strengthened the process and resulting ACE Strategic Planning Framework.

The dialogue design employed a collaborative and iterative planning process that allowed participants to decide the priorities for the dialogues, which made the sessions both resource- and time-efficient. The coordinating team of the initiative followed UN best practices for building an ACE national strategy (UNESCO and UNFCCC 2016; UNESCO 2020), adapting them to fit the unique national circumstances of the US. To better reflect existing ACE infrastructure, the team condensed the six officially recognized ACE elements into four intersecting categories: transformational learning and engagement; inclusive and responsible community engagement in decision-making; training a climate-ready workforce; and sectoral, subnational, national, indigenous, and international coordination and collaboration.

\section{i. Guiding principles}

The guiding principles of the ACE Strategic Planning Framework process came out of discussions rooted in the US context but are salient in ACE work, nationally or subnationally, anywhere in the world. Examples of how the principles were applied in practice are detailed in the descriptions of different components of the project below.

\section{Justice and equity}

The dialogue process and the resulting ACE Strategic Planning Framework sought to acknowledge histories of oppression and actively deconstruct the systems and institutions perpetuating it. Process design iterations helped to foster new ways to name and resolve tensions resulting from histories of colonialism, marginalization, and unequal distribution of power in government, society, and environmental policy.

\section{Action oriented}

Part of building trust into the process was managing a conducive environment for concrete policy recommendations and maximizing cooperation (Hale and Hultman 2020, Klein and Juhola 2014). This process was designed as a strategy for envisioning a collective climate resilient future, identifying the role of ACE to enable that vision, and providing structured and concrete policy recommendations to provide structural supports and regulations for the work. 


\section{Coherence}

The process acknowledged that complex layers of governance and self-determination involving governments, organizations, and communities across different scales exist and influence how ACE activities are coordinated. Coordination of ACE work across this complex governance landscape seeks to foster efficiency and coherence of the effort (Bocquillon 2018; Hahn, Harris and Corner 2016; Bieler et al. 2017). Networks can bring new learning from this collective work back into their local activities. They can also inform how broader coordination and coherence efforts need to be structured (e.g., funding, policy, and capacity building supports) in iterative and timely ways.

\section{Relationality}

Changing the way we have worked to better foster and accelerate climate action requires us to work in trusting relationships with each other (Gould et al. 2019; Maibach 2019). Due to historical breaches of trust, some relationships between ACE community members-individuals, organizations, institutions, businesses, communities, and governments-need to be repaired. Additionally, cultural differences across diverse communities requires that the process includes those who can bridge different communities and support others to do so as well (Luo 2007). This principle of relationality also applies to efforts to broker international sharing about ACE efforts and how to hold nations accountable to this work.

\section{Participatory collaborative design}

Collectively, the above principles lead us to integrate principles of participatory design in working in and with communities around environmental justice. These principles, which have emerged in the research record over the past decade, are rooted in communities with deep histories of civic action and environmental protection (Bang and Vossoughi 2016; Barton et al. 2015; Penuel et al. 2020). Deeply involving people and communities in the design of policies and implementation strategies ensures the creation of more ambitious, effective, and adaptive solutions rooted in local needs, capabilities, and actions. Wider engagement also makes the policy design process smarter by allowing political will to emerge from both shared and localized climate action insights. Community and dialogue-based policymaking is key to identifying, activating, and coordinating individuals and organizations for massive change towards a just, resilient, and sustainable future.

ii. The ACE Strategic Planning Framework process engaged these guiding principles and was informed by UN best practices for building an ACE national strategy (UNFCCC 2012; UNESCO and UNFCCC 2016; UNESCO 2020). Below, we share the different components of the creation of the ACE Strategic Planning Framework in a narrative form, including the formation of the coordinating team, initial landscape analysis of the ACE community, design of our participatory practices, collaboration strategies, ACE dialogue conversation design, writing and review process, and sharing of the work with others.

\section{Coordinating team}

The ACE Strategic Planning Framework developed out of decades of work by ACE practitioners and networks and began to coalesce more formally through a series of meetings and workshops over the past three years. These discussions ended in consensus: the only way that an ACE national strategy could be truly effective is if it was developed by ACE practitioners in a new and participatory way that would disrupt historic power structures and uplift the values of marginalized groups.

Building on workshops and listening sessions, the ACE community assembled an eleven-member coordinating team to spearhead these efforts, including experts from government, civic diplomacy, formal and informal education institutions, social movements, non-governmental organizations, strategic communication, workforce development, private sector, and members of the community with deep knowledge on ACE-related work. A key to success in stakeholder engagement was the 
identification of individuals with different strengths and positions to build trust in the process. Consideration was given to the diversity of voices of the people in the room, as well as compensation and workload to reduce barriers to participation and increase equity within the coordinating team and in other leadership roles. As the planning process continued, the coordinating team grew and split into two main groups: logistics, who handled day to day details, and advisory, who provided guidance and connections. This division allowed people to choose their level of involvement and work in areas conducive to their strengths, which engaged the notion of collaborative work built on community cultural wealth (Yosso 2005). This strategy greatly improved the racial, socioeconomic, and ideological diversity of the coordinating team and made the strategic planning process stronger overall.

\section{Ensuring and facilitating diverse participation}

Participation of marginalized communities in policy making needs to be supported, incentivized, and funded. Peoples marginalized in societies need power and meaningful avenues to influence policy making to ensure that historic inequities are identified and mitigated as part of process design and in resulting recommendations and implementation efforts. The coordinating team, diverse in age, gender, geography, and experience but relatively limited in racial diversity, endeavored to build diversity and equity into all aspects of the process. Drawing from networks and databases, dialogue participants were added to an invitee list. Throughout the entire process, the coordinating committee added members and ensured the stratified list of participants, speakers, facilitators, and rapporteurs provided a representative sample according to age, gender, ethnicity, background, and stakeholder group from across the nation's ACE efforts and disciplines. All speakers, facilitators, and rapporteurs were compensated for their participation.

The participant list was reviewed and developed at weekly coordinating team meetings. These meetings also focused on logistics, developing a facilitation guidebook, and the selection of an appropriate pool of facilitators and rapporteurs for the dialogues. Facilitator and rapporteur training was also provided prior to the dialogues. The team paid particular attention to inclusivity, encouraging conventionally excluded groups such as those people experiencing historic and climate marginalization to attend the dialogues and participate in leadership roles. The coordinating team developed a matrix of 464 invitees that they identified as experts in an ACE element and/or keys to making the process successful. To ensure representation of all the ACE elements, the matrix included notes about which areas and subsections of ACE representation (see Figure 2). To better fit national circumstances, the team also specifically invited ACE-related practitioners from frontline communities, tribal nations, branding and strategic communication, anti-racist work, and climate justice. Measurement, evaluation, philanthropy, and funding representatives were included to facilitate and provide guidance on the process.

\section{iii. Our participatory approach: Talanoa and backcasting}

Talanoa is a traditional, inclusive, participatory, and transparent dialogue approach practiced by the indigenous communities in Fiji and the Pacific (UNFCCC 2018). The Fijian word 'Talanoa' refers to an inclusive process of dialogue where all participants, regardless of power or influence, are peers. The approach is designed to share stories in an environment with built-in trust and empathy. This Indigenous methodology must be recognized as a tool that emerged from decolonization efforts for indigenous sovereignty and self-determination, particularly with respect to climate action (Ludi et al. 2018; Nhamo 2018, Mundaca et al. 2019). It creates a space for dialogue where multi-level participants can co-create strategies through common understanding, resulting in stronger decision-making for everyone. The Talanoa dialogue process answers three guiding 


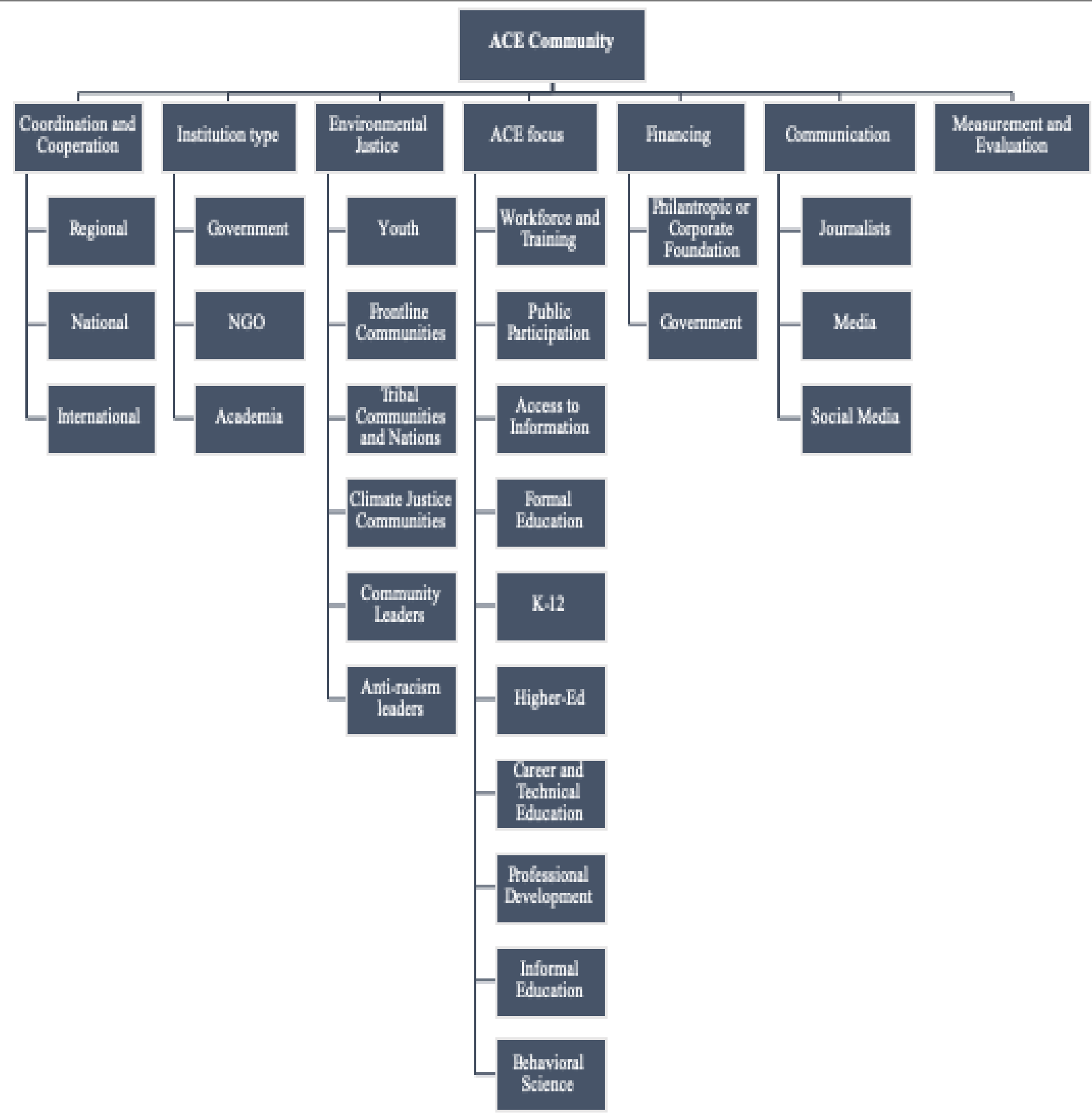

Figure 2: Matrix of ACE community representation.

questions: Where are we? Where do we want to be? How do we get there?

The US ACE dialogues embraced the Talanoa process, setting the stage for collaborative and actionoriented open conversations focused on creating a shared vision rather than the promotion of individual projects or methodologies. The Talanoa style leveled existing and perceived hierarchies among participants and promoted meaningful conversations and relationship building while collaboratively creating policy recommendations.

Following the Citizens' Climate Engagement Network (CCEN) Engage4Climate toolkit (CCEN 2015), the dialogues were facilitated in the Talanoa spirit through facilitative questions and a backcasting approach based on a 20-year visioning process and mapping out action steps in ten-, five-, and two-year timeframes. The backcasting method included four main steps: 
1. Problem definition and identification of priorities for what is to be achievedPriorities established by the participants through asynchronous surveys were used as part of the guiding questions for the dialogue.

2. Development of a collective vision for 2040Framing the conversation initially in terms of the social and scientific necessities for where the country needs to be in 2040 , rather than how to make progress from where we are now, encouraged creativity, reduced cynicism related to political will, and deemphasized discussion of individual plans, programs, and legislation. This change in perspective allowed a truly shared vision of the path to building a transformative national ACE effort to emerge.

3. Analysis of present potential and future challenges for achieving targets-Participants leveraged the experience and knowledge of everyone involved to determine the main challenges to scale-up and implementation of their vision for ACE at the national level.

4. Goal setting for 10, 5, and 2 year horizonsThis backcasting process saw participants describing what an empowered, informed, and active society would look like in 2040 and creating goals sufficient to achieve that 20year vision at 10,5 , and 2 year intervals, in that order.

At the beginning of the process, there was no specification of metrics, such as a greenhouse gas reduction target, to be met by the 2040 vision. Instead, all targets and goals were set collaboratively by the community. Expectations around the inclusion of social and environmental justice and a communitycentered approach were set at the launch event and reinforced by facilitators, but these priorities again stemmed from input from the ACE community.

iv. Working across distances: virtual dialogue environment
Historically, it was not thought possible to work virtually across diverse communities in respectful and meaningful ways; however, due to the COVID-19 pandemic, all aspects of the ACE Strategic Planning Framework were conducted using virtual tools. Dialogue events were convened over Zoom with the launch and community review launch events conducted as webinars and the four dialogues themselves run as Zoom meetings. All events were recorded to assist the writing team to faithfully capture all thoughts shared, and the launch event webinars were posted online for reference by participants.

Several benefits to this virtual approach were identified. The virtual environment provided expanded transparency, improved accessibility for participation, and reduced the carbon footprint of the overall process. In addition, the synchronous and asynchronous work leveled the playing field, broke status barriers and allowed people to participate with few resources and low time commitments.

\section{v. Designing visions for ACE: the dialogues}

The development of An ACE Strategic Planning Framework for the United States involved a series of dialogues during the month of August 2020. The launch event on August 6, 2020 introduced the background of the project, outlined the process, and explained the critical intersection of ACE and climate justice work. Speakers included public officials, activists, academics, environmental justice luminaries, and representatives of communities on the front line of climate change. The launch event set a shared foundation of understanding of the U.S. national context, the scope of the full range of ACE elements, highlight the central importance of justice to the ACE process and vice-versa, and the value of ACE for community-driven decision making.

To address intersectionality between ACE elements, the six officially recognized ACE elements were condensed into four intersecting pathways, each the focus of a dialogue session: (1) transformational learning and engagement; (2) inclusive and 
responsible community engagement in decisionmaking; (3) training a climate-ready workforce; and (4) sectoral, sub-national, national, Indigenous, and international coordination and collaboration. These dialogue sessions were conducted over two weeks in August of 2020. Synthesized surveyed priorities were used to determine major topics of interest with respect to the dialogue theme. These broad topics were assigned to a "breakout group" with a facilitator and rapporteur. The priorities and breakout groups were refined during the beginning of the pathway dialogues to ensure it was reflective of the collective thinking and that all groups were kept to 10 participants or less. After a Zoom poll, if a category had more than 10 interested participants, it would be split into two groups to allow for more active and nuanced conversation. Groups with 3-6 participants, not including the facilitator and rapporteur, allowed a richness of discussion, coverage of thematic areas and development of concrete action-oriented outcomes. To allow for all thoughts to be recorded, each breakout was held in a separate Zoom meeting. Meeting links and breakout group topics, as well as launch event speaker bios and other important information updated in real time, were made accessible to attendees in a dynamic "Roadmap" that guided attendees through the entire process. Once in breakout rooms, dialogue facilitators led the conversations and rapporteurs recorded the discussion. As part of the effort to disrupt traditional power structures and ensure that conversations reflected the entire community, priority was given to Black and Indigenous and People of Color (BIPOC) when recruiting facilitators and rapporteurs.

At the end of each dialogue, facilitators and rapporteurs reported back to the full plenary a summary of their conversation before the session adjourned. Within 24 hours of the end of a dialogue, facilitators, rapporteurs, and a synthesis lead, chosen by the coordinating team for their expertise in the dialogue topic, compiled and emailed to all participants of the entire process a two page synthesis report of the dialogue. Keeping reports kept everyone informed of the context and tone of the conversation and assisted in the development of a cohesive strategy over four dialogues spread over two weeks.

\section{vi. Review and writing process}

After all dialogues, a nimble two-person team of writers drafted the ACE Strategic Planning Framework based on the synthesis reports, rapporteur notes, and recordings of the breakout groups. The writing team members were chosen intentionally for their deep expertise in ACE and experience with different types of power and knowledge; academia, local government, small business, frontline communities, and federal perspectives were all considered in the framing and language of the ACE Strategic Planning Framework. Crucially, these considerations did not affect the content of the ACE Strategic Planning Framework; the Talanoa process results in community-centered policy, rather than being written for government sensibilities. To honor the spirit of the Talanoa process and the principle of equity, the writing team gave weight to every point that came out of the dialogues in order to best represent the contributions of participants. To the degree possible, the writers endeavored to include comments as they were given, rather than processing them through filters of political expediency or personal opinion. The intent to reflect the will of the dialogue participants is critical to the Talanoa process; the writers' job is to execute on paper what the process does in conversation, not fit it to a preexisting agenda. Reflecting the will of the participants required a constant process of reflection and humility around biases on behalf of the writers. To ensure this was done, an extensive review process was woven in iteratively to the writing process.

Review of the draft Strategic Planning Framework was conducted in three steps: (1) by the coordinating team, (2) by a select group of strategic reviewers invited for their expertise and leadership in various aspects of ACE, and (3) by the dialogue participants and the larger ACE community. The coordinating team edited the first draft for major omissions and 
framing issues. The strategic review, conducted by diverse subject experts not involved in the dialogues, ensured that the ACE Strategic Planning Framework was as properly constructed and representative of the breadth of the ACE work. The community review invited all participants and additional actors of ACErelated efforts to give feedback on the Framework document. To facilitate the community review we used a mechanism, modeled from the IPCC review process, for reviewers to input their comments to a line-numbered document. For full transparency, we tracked all suggestions and responses to comments from the writing team.

\section{vii. Circulation and coalition building}

After incorporating comments and suggestions, the ACE Strategic Planning Framework was finalized and distributed to participants, networks and key ACE community leaders identified by the coordinating team. Organizations and individuals were invited to become signatories to the ACE Strategic Planning Framework to show their support. Additionally, outreach efforts on the scope, design and outcomes of the process have been carried out through policymaker and stakeholder briefings, workshops, and through the United Nations Climate dialogues.

\section{Conclusions}

This community-driven participatory methodology combining backcasting and Talanoa dialogue approaches for strategic planning created widespread buy-in from key stakeholders from the US ACE community. The methodology is a novel approach that facilitates shared understanding and alignment and saves time and resources. Dialogue participants, reviewers, and the vast facilitation team recognized the community driven approach described in the case of the ACE Strategic Planning Framework process in the United States as beneficial to fostering justice in climate change policy making. The Talanoa dialogue process was an effective way to amplify marginalized voices in decision-making arenas and to learn from and with each other across different communities working towards climate justice (Bowman and Morrison 2021, 82-92). These practices shifted who was heard and how expertise was positioned, illuminating how knowledge and innovation is dispersed across multiple contexts and communities.

As a result of our approach, many participants recognized that the boundary spanning role of ACE should underpin all climate action to ensure public engagement and that involvement, design and implementation responds to local needs and capabilities. Moreover, an ACE National Strategy would enable and encourage cross-sector collaboration and coordination for climate action in a model that encompasses local participation, leadership, and consent. Collaborative design and learning helped engage those normally siloed into discrete spaces in collaborative, interdisciplinary and intersectional work to accelerate all types of climate action. The outcomes from this process suggest that fostering cross-community communication practices and informed engagement in collaborative design, as ACE implies, increases the odds of fulfilling the transformative potential of bold climate action and participatory decision-making (Fleming and Waguespack 2007).

Purposefully engaging diverse communities and networks in this collaborative visioning and design work allowed for strategic positioning of this work across many different scales. In order to attain this, it was necessary to shift who defined national ACE priorities. This required new ways of organizing, collaborating, and being rooted in relation to one another, grounded in the principles identified above. Engaging in this way in ACE has the potential to create pathways for broad civic support to accelerate climate action and repair historically fractured relationships between diverse communities, governments, and organizations by building respect and understanding as people engaged in shared work.

In conclusion, enacting Action for Climate Empowerment using participatory collaborative design practices has the potential to accelerate 
climate action through engaging diverse community thought and fostering broad-based support for ambitious climate policy that is responsive to community needs and capabilities. In line with the ACE elements, as a result of this work, the authors offer the following recommendations for policymakers to ensure equitable and just design of effective climate and resilience policy:

1. Openness and accountability-Policy making should have timely and up-to-date information available through all stages of decision making for effective participation.

2. Participatory design practices-Climate and resilience policies should be built and implemented through multilevel consultations with affected groups and networks that give them authentic decisionmaking authority and authorship on ACE work.

3. Prioritization of marginalized groupsParticipation of marginalized communities and networks needs to be supported in all ways possible, including funding and developing adequate pathways for participation.

In order to develop effective, groundbreaking, and collaborative ACE policy to most impactfully design and accelerate climate action, we need to ensure that the ideas, values, and knowledge of all affected communities are considered. To truly have such diversity of thought and being in the world present in decision making, we need to ensure that not only are all given space to speak and share but also that everyone is seeking understanding of different perspectives and approaches (Bowman and Morrison 2021). It is through this new and transformative process of co-designing policy with marginalized and affected communities and the groups that will implement the policy, that truly equitable, effective, and empowering climate policy can be developed.

\section{References}

Bang, Megan, and Shirin Vossoughi. 2016. "Participatory Design Research and Educational Justice: Studying Learning and Relations Within Social Change Making." Cognition and Instruction 34, no. 3, 173193, https://doi.org/10.1080/07370008.2016.118187 9.

Barton, Jonathan Richard, Kerstin Krellenberg, and Jordan Michael Harris. 2015. "Collaborative Governance and The Challenges of Participatory Climate Change Adaptation Planning in Santiago de Chile." Climate and Development 7, no. 2: 175-184. https://doi.org/10.1080/17565529.2014.934773.
Bhowmik, Avit K., Mark S. McCaffrey, Abigail M. Ruskey, Chad Frischmann, and Owen Gaffney. 2020. "Powers of 10: Seeking 'Sweet Spots' for Rapid Climate and Sustainability Actions Between Individual and Global Scales." Environmental Research Letters 15, no. 9. https://iopscience.iop.org/article/10.1088/17489326/ab9ed0/meta.

Bibri, Simon. 2018. "Backcasting in Futures Studies: ASynthesized Scholarly and Planning Approach to Strategic Smart Sustainable City Development". European Journal of Futures Research 6, no. 13. https://doi.org/10.1186/s40309-018-0142. 
Bieler, Andrew, Randolph Haluza-Delay, Ann Dale, and Marcia Mckenzie. 2017. "A National Overview of Climate Change Education Policy: Policy Coherence Between Subnational Climate and Education Policies in Canada (K-12)." Journal of Education for Sustainable Development 11, no. 2: 63-85. https://doi.org/10.1177/0973408218754625.

Bifulco, Lavinia. 2013. "Citizen Participation, Agency and Voice" European Journal of Social Theory 1, no. 2: 174-187. https://doi.org/10.1177/1368431012459695.

Bocquillon, Pierre. 2018. "(De-) Constructing coherence? Strategic Entrepreneurs, Policy Frames and the Integration of Climate and Energy Policies in the European Union." Environmental Policy and Governance 28, no. 5: 339-349. https://doi.org/10.1002/eet.1820.

Borick, Christopher P. and Barry G. Rabe. 2010. "A Reason to Believe: Examining the Factors that Determine Individual Views on Global Warming." Social Science Quarterly 91: 777-800. https://doi.org/10.1111/j.15406237.2010.00719.x.

Bowman, Tom, and Deb Morrison, eds. 2021. Empowering Climate Action in the United States. Washington, D.C. and Winchester, UK: Changemakers Books. Forthcoming.

Bullard, Robert D., ed. 1993. Confronting Environmental Racism: Voices from the Grassroots. Cambridge, MA: South End Press.

Bullard, Robert D., ed. 2005. The Quest for Environmental Justice: Human Rights and the Politics of Pollution. San Francisco: Sierra Club Books.

Bullard, Robert D., Maaz Gardezi, Carrie Chennault, Hannah Dankbar. 2016. "Climate Change and Environmental Justice: A Conversation with Dr. Robert Bullard." Journal of Critical Thought and Praxis 5, no.2. https://doi.org/10.31274/jctp180810-61.

Campos, Inês S., Filipe M. Alves, João Dinis, Monica Truninger, André Vizinho, and Gil Penha-Lopes. 2016 "Climate Adaptation, Transitions, and Socially Innovative Action-research Approaches." Ecology and Society 21, no. 1. https://www.jstor.org/stable/26270323.

CCEN. 2015. Engage4Climate Toolkit. Paris, France. Accessed August 2020 at http://engage4climate.org/talanoa-toolkit.

Creutzig, Felix, Blanca Fernandez, Helmut Haberl, Radhika Khosla, Yacob Mulugetta, and Karen C. Seto. 2016. "Beyond Technology: Demand-Side Solutions For Climate Change Mitigation". Annual Review of Environment And Resources 41 (1): 173-198. http://doi:10.1146/annurev-environ-110615$\underline{085428 .}$
Feola, Giuseppe, and Richard Nunes. 2014. "Success and failure of grassroots innovations for addressing climate change: The case of the Transition Movement." Global Environmental Change 24: 232-250.

https://doi.org/10.1016/i.gloenvcha.2013.11.011

Figueres, Christina. 2015. "Action for Climate Empowerment." Opening Speech, ACE annual Dialogue on Article 6, Bonn, Germany.

Fleming, Lee, and David M. Waguespack. 2007. "Brokerage, Boundary Spanning, and Leadership in Open Innovation Communities." Organization Science 18, no. 2: 165-180. https://doi.org/10.1287/orsc.1060.0242.

Ghojeh, Mehrnaz, Caterina Sarfatti, Sabrina Uffer, Mikayla Hoskins, Robert Mayers, and David Bigio. 2019. Inclusive Climate Action in Practice. London: C40 Cities.

Gould, Rachelle K., Māhealani Pai, Barbara Muraca, and Kai MA Chan. 2019. "He 'ike 'ana ia i ka pono (it is a recognizing of the right thing): how one indigenous worldview informs relational values and social values." Sustainability Science 14, no. 5: 1213-1232. https://doi.org/10.1007/s11625-01900721-9.

Hahn, Ulrike, Adam JL Harris, and Adam Corner. 2016. "Public Reception of Climate Science: Coherence, Reliability, and Independence." Topics in Cognitive Science 8, no. 1: 180-195. https://doi.org/10.1111/tops.12173.

Hale, Thomas and Nathan Hultman. 2020. 'All in' Climate Diplomacy: How a Biden-Harris Administration Can Leverage City, State, Business, and Community Climate Action. Washington D.C.: Brookings Institution. https://www.brookings.edu/wpcontent/uploads/2020/11/All-in-climatediplomacy final.pdf.

Haverkamp, J. 2021. Collaborative Survival and the Politics of Livability: Towards adaptation otherwise. World Development, 137, 105152. https://doi.org/10.1016/..worlddev.2020.105152.

Kang, Sungkuk, and Ibrahim Ajaja. Climate Frontlines, UNESCO, 2015, https://climatefrontlines.org/.

Klein, Richard J. T. and Sirkku Juhola. 2014. "A Framework for Nordic Actor-oriented Climate Adaptation Research." Environmental Science \& Policy 40: 101-15. https://doi.org/10.1016/j.envsci.2014.01.011.

Kwauk, Christina and Olivia Casey. 2021. A New Green Learning Agenda: Approaches to Quality Education for Climate Action. Washington D.C.: Brookings Institution. https://www.brookings.edu/wpcontent/uploads/2021/01/Brookings-GreenLearning-FINAL.pdf. 
Leiserowitz, Anthony. 2019. "Building Public and Political Will for Climate Change Action," in A Better Planet: 40 Big Ideas for A Sustainable Future edited by Daniel Etsy, 155-162. New Haven and London: Yale University Press.

Ludi, Eva, Erin Roberts, Rebecca Nadin, Margherita Calderone, Rajeshree Sisodia, Guy Jobbins, and Nathalie Nathe. 2018. Unlocking Climate-resilient Economic Development in Drylands: Pathways to a Resilient World: Submission to the Talanoa Dialogue. London: Overseas Development Institute https://www.odi.org/sites/odi.org.uk/files/resourc e-documents/12488.pdf.

Luo, Yadong. 2007. "The Independent and Interactive Roles of Procedural, Distributive, and Interactional Justice in Strategic Alliances." Academy of Management Journal 50, no. 3: 644664. https://doi.org/10.2307/20159877.

Maibach, Edward. 2019. "Increasing Public Awareness and Facilitating Behavior Change: Two Guiding Heuristics." Climate Change and Biodiversity. https://www.climatechangecommunication.org/ wp-content/uploads/2018/06/Maibach-Twohueristics-September-2015-revised.pdf.

Morrison, D. L. 2020. Accelerating Just Climate Action through the Elements of the Action for Climate Empowerment Program. Retrieve from http://bit.ly/ACEElements

Mundaca, Luis, Jonas Sonnenschein, Linda Steg, Niklas Höhne, and Diana Ürge-Vorsatz. 2019. "The Global Expansion of Climate Mitigation Policy Interventions, The Talanoa Dialogue and The Role of Behavioural Insights." Environmental Research Communications 1 no: 6. https://iopscience.iop.org/article/10.1088/25157620/ab26d6.

National Research Council. 2011. America's Climate Choices. Washington, D.C.: The National Academies Press. https://doi.org/10.17226/12781.

Nhamo, Godwell. 2018. "UNFCCC decision on agriculture: Africa Must Continue Prioritising Adaptation in the Talanoa Dialogue and (I) NDC Processes." South African Journal of International Affairs 25, no. $\quad 3$ : 281-299. https://doi.org/10.1080/10220461.2018.152227 $\underline{5 .}$

Penuel, William R., Robbin Riedy, Michael S. Barber, Donald J. Peurach, Whitney A. LeBouef, and Tiffany Clark. 2020. "Principles of Collaborative Education Research with Stakeholders: Toward Requirements for A New Research and Development Infrastructure." Review of Educational Research 90, no. 5: 627-674. https://doi.org/10.3102/0034654320938126.
Pellow, David N., and Robert J. Brulle. 2005. Power, Justice, and the Environment: A Critical Appraisal of the Environmental Justice Movement. Cambridge, MA: MIT.

Rabe, Barry G. 2010. "Introduction: The Challenges of US Climate Governance." in Greenhouse Governance: Addressing Climate Change in America, 3-23. Washington, DC: Brookings Institution Press.

Rare and The Behavioral Insights Team 2019. Behavior Change for Nature A Behavioral Science Toolkit for Practitioners. Arlington, VA: Rare. Sautier, Marion, Mathilde Piquet, Michele Duru, and Roger MartinClouaire. 2017. "Exploring Adaptations to Climate Change with Stakeholders: A Participatory Method to Design Grassland-based Farming Systems." Journal of Environmental Management 15, no. 193: 541-550. https://doi.org/10.1016/i.jenvman.2017.02.050.

Sprain, Leah. 2017. "Paradoxes of public participation in climate change governance." The Good Society 25, no. 1 : 62-80. https://doi.org/10.5325/goodsociety.25.1.0062.

UNDESA, UNDP, and UNESCO. 2012. Governance and Development: Thematic Think Piece https://www.un.org/millenniumgoals/pdf/Think\% 20Pieces/7 governance.pdf.

UNESCO. 2020. Integrating Action for Climate Empowerment Into Nationally Determined Contributions: A Short Guide for Countries. Paris, France: United Nations Educational, Scientific and Cultural Organization (UNESCO). https://unesdoc.unesco.org/ark:/48223/pf0000 373762.

UNESCO and UNFCCC. 2016. Action for Empowerment: Guidelines for Accelerating Solutions Through Education, Training and Public Awareness. Paris, France: United Nations Educational, Scientific and Cultural Organization (UNESCO). https://unfccc.int/files/cooperation and support/ education and outreach/application/pdf/action for climate empowerment guidelines.pdf.

UNFCCC. 2012. Doha Work Programme on Article 6 of the Convention. Subsidiary Body for Implementation, reference no. FCCC/SBI/2012/L.47. Doha, Qatar: United Nations Framework Convention on Climate Change (UNFCCC). https://unfccc.int/resource/docs/2012/sbi/eng//4 7.pdf.

UNFCCC. 2018. "2018 Talanoa Dialogue Platform." Accessed January 9, 2021. https://unfccc.int/process-and-meetings/theparis-agreement/the-paris-agreement/2018-tal anoa-dialogue-platform. 
United Nations General Assembly. 1948. "Universal Declaration of Human Rights." Proclamation date: 10 December 1948. Resolution 217 A. Paris. https://www.un.org/en/universal-declarationhuman-rights/.

United Nations General Assembly. 1992. "United Nations Framework Convention on Climate Change." Conclusion date: 14 June 1992. United Nations Treaty Series Online, registration no. I-30822. https://treaties.un.org/doc/Publication/UNTS/Vol ume\%201771/v1771.pdf.

United Nations General Assembly. 2007. "United Nations Declaration on the Rights of Indigenous Peoples." Resolution 61/295. New York. https://undocs.org/A/RES/61/295.

United Nations General Assembly. 2015. "Paris Agreement." Conclusion date: December 12, 2015. United Nations Treaty Series Online, registration no.

I-54113. https://treaties.un.org/doc/Publication/UNTS/No $\% 20$ Volume/54113/Part/l-54113$\underline{0800000280458 f 37 . p d f}$
Van der Linden, Sander, Anthony Leiserowitz, Seth Rosenthal, and Edward Maibach. 2017. "Inoculating the Public against Misinformation about Climate Change." Global Challenges: Climate Change 2017. https://doi.org/10.1002/gch2.201600008.

Wolfram, Marc, Jeroen van der Heijden, Sirkku Juhola, and James Patterson. 2019. "Learning in Urban Climate Governance: Concepts, Key Issues and Challenges." Journal of Environmental Policy \& Planning 21, no. 1: 1-15. https://doi.org/10.1080/1523908X.2018.15588 48.

Yosso, Tara J. 2005. "Whose Culture Has Capital? A Critical Race Theory Discussion of Community Cultural Wealth." Race, Ethnicity and Education 8, no. 1:6991.

Isatis M. Cintron-Rodriguez is a Puerto Rican climate researcher awarded the National Science Foundation (NSF) Graduate Research Fellowship and the Austrian Science Fund to study the impacts of atmospheric pollution in the cryosphere and potential mitigation policies. She works in the intersection between climate civic diplomacy, science and community organizing around climate action and human rights in the Latin America and Caribbean Region (LAC). She is the LAC Regional Coordinator for Citizens Climate Lobby/International (CCI), focused on advancing climate-smart finance, climate empowerment, and public participation both at the national and the UNFCCC level. She also manages and designs engagement strategies for civil society, scientists, and policymakers across the world at the local, national and international level. She is also a member of the U.S. ACE Framework Coordinating Team. Her work has been supported by the Union of Concerned Scientists to hold a citizens' assemblies to build a National Climate Action Strategy for Puerto Rico, a template that has served to coordinate and deploy citizens assemblies across the LAC region.

Haley A. Crim is a project coordinator at the Climate Literacy and Energy Awareness Network (CLEAN) and a member of the U.S. ACE Framework Coordinating Team. Her work focuses on coordinating communities, governments, nonprofits and other stakeholders to work together towards climate justice. Haley recently graduated Cum Laude from Bates College with a degree in Ecology and Earth Systems and served in AmeriCorps' Greenest Region Corps as a sustainability fellow at the Village of Park Forest, Illinois.

Deb L. Morrison, PhD works at the intersection of justice, science, and learning. She is a scientist, educator, learning scientist, mother, and locally elected official. Deb works in research-practice-policy partnerships across various scales to iteratively understand and improve complex socio-ecological systems through designbased and action-oriented research. More at www.debmorrison.me 
Frank Niepold serves as the Climate Education Coordinator at NOAA's Climate Program Office in Maryland, and U.S. ACE National Focal Point. He is a co-chair of the U.S. Global Change Research Program's Education Interagency Working Group, member of the Federal Steering Committee for the Fourth National Climate Assessment, and the ECOS community. He is the reporting lead for the UNFCCC National Communication Education and Youth Chapter. Niepold is a founding member and co-chair of the CLEAN Network Leadership Board. He has been a delegate for the U.S at the 2015 UN COP21.

Jen Kretser leads the Wild Center's climate change engagement program including the Youth Climate Program which works to engage with and empower youth around the world to take action on Climate Change. Under her direction, the Program has been recognized by the White House and the Environmental Protection Agency. She has represented the Wild Center at the United Nations climate talks. Kretser is also part of the coordinating team for U.S. ACE Framework, the CLEAN Network Leadership Board and the NYC Climate Resilience and Education Task Force.

William Spitzer, PhD is a member of the coordinating team for the U.S. ACE Framework, and is former Vice President for Learning and Community at the New England Aquarium, where he was responsible for applying learning and social science research across education programs, exhibits, visitor experience, and community outreach for more than 20 years.

Tom Bowman is a strategic communication practitioner, consultant, and author in the fields of climate change engagement and business strategy. He is founder of Bowman Design Group and Bowman Change, Inc., a consultancy that advises government agencies and cultural institutions.

Acknowledgements We thank Spencer Foundation for making this work possible under Grant No. 202100079. We would also like to show gratitude to the broad ACE community for sharing their lived experience and practical wisdom with us in this process. We stand on the shoulder of giants.

Disclaimers This paper is based upon the ACE community insights and might not necessarily reflect the views of Spencer Foundation or the authors' institutions and governmental agencies. 